\title{
Cost-benefit analysis: New foundations on shifting sand
}

\section{A review of Matthew D. Adler and Eric A. Posner's New Foundations of Cost-Benefit Analysis (Harvard University Press, 2006)}

\author{
Amy Sinden \\ Temple University Beasley School of Law, Philadelphia, PA, USA \\ Douglas A. Kysar \\ Yale Law School, New Haven, CT, USA \\ David M. Driesen \\ Syracuse University College of Law, Syracuse, NY, USA
}

\begin{abstract}
New Foundations of Cost-Benefit Analysis, by Matthew Adler and Eric Posner, represents the most ambitious and credible effort to date to build a solid theoretical defense of the use of cost-benefit analysis (CBA) in evaluating government regulation. In this review, three cost-benefit "skeptics" offer their reactions to this ambitious and important book. We note its virtues - its humility, its scrupulousness, its open-mindedness. We also explore its vices. If preferences are to be "laundered," is it intellectually defensible to remove the bad but not consider adding the good? Does Adler's and Posner's welfarism really play the limited role they suppose, or does it risk "crowding out" other important deontological and distributional values? If CBA is merely a decision procedure that provides an imperfect proxy of welfare - the moral criterion we really care about - how do we know that the proxy it provides in practice will actually be accurate enough to be useful? Isn't this at bottom an empirical question that cannot be answered by this thoroughly theoretical book? If CBA is no more than an imperfect proxy for welfare, then alternative imperfect decision procedures may perform better in the real world.
\end{abstract}

Keywords: cost-benefit analysis, economics, environment, regulation.

\section{Introduction}

The political landscape is shifting. The financial crisis has brought the dangers of unfettered free markets into stark relief and prompted leaders from both parties to advocate massive government intervention. And even before stocks began to plunge, a national consensus had begun to emerge on the need for government regulation to stem another global crisis - the steady, ominous rise in global temperatures. These dramatic events may

Correspondence: Amy Sinden, 1719 N. Broad Street, Philadelphia, PA 19122, USA. Email: amy.sinden@temple.edu

Accepted for publication 8 February 2009. 
be ushering in a new era in which regulation re-emerges as an accepted function of government.

But what does good regulation look like? And how can we tell it when we see it? Some argue that cost-benefit analysis (CBA) is the best way to separate the good regulation from the bad - the socially useful regulation from the wasteful and corrupt. Granted, CBA has a checkered past. In the US, it was first introduced into widespread use in federal agency decision-making by Ronald Reagan at the behest of persistent industry lobbyists, who clearly viewed it as a tool for squelching and delaying regulation. But it survived the demise of that anti-regulatory era: President Clinton continued the practice. There are now even scholars on the political Left, including a former environmental activist, calling for its continued use (Revesz \& Livermore 2008).

In the academic literature, a fierce debate over the theoretical foundations of CBA has raged for decades (Tribe 1972; Mishan 1976). Critics early on identified significant flaws in the theoretical justification for CBA that its proponents never successfully refuted (Leff 1974; Baker 1975; Kennedy 1981). But several years ago, a few legal scholars began to suggest a different approach to the defense of CBA. Cass Sunstein suggested the idea of a "pragmatic" defense of CBA in broad strokes (Sunstein 2002b), but it was Matthew Adler and Eric Posner who painstakingly and thoroughly began to work out the details of that defense in a series of law review articles (Adler 1998, 2000, 2003; Adler \& Posner 1999, 2000; Posner 2001). And now, that effort has culminated in a book by Adler and Posner, New Foundations of Cost-Benefit Analysis (Adler \& Posner 2006). This book does indeed suggest innovative foundations for the theoretical defense of CBA, injecting new life into a decades-old debate.

The traditional defense of CBA under economic theory casts it as a direct measure of efficiency. Under this view, a regulation that meets a CBA test is efficient in the economic sense; that is, it maximizes overall welfare (Mishan 1976). This defense offers all of the appeal of economic theory more generally. Perhaps most importantly, it seems to offer a neat mathematical equation for solving messy social problems. At the same time, it is vulnerable to most of the major criticisms that plague economic theory, like the inadequacy of willingness to pay as a measure of value.

Adler's and Posner's central innovation is to decouple CBA from overall welfare. Rather than arguing that CBA directly measures overall welfare, they concede from the outset that even in theory, the fit between CBA and overall welfare is no more than a rough approximation. Nonetheless, they argue, this "rough and ready proxy" is good enough for government work (p. 25). This allows them to concede, rather than fight, some of the central critiques of welfare economics, like the problem of wealth effects. Rather than having to deny the existence of these problems, Adler and Posner can sidestep them by acknowledging their existence but simply trying to convince the reader that they do not create big enough distortions to pose a problem.

Their basic argument comes in two parts. The first step is to convince the reader that we should care about overall welfare. Here again, they wisely avoid making the kind of ambitious claim that can be appealing yet vulnerable to criticism. Rather than taking the utilitarian hard line and arguing, as so many law and economics scholars have (Kaplow \& Shavell 2002), that overall welfare is the only relevant moral criterion for most policymaking outside of the tax and transfer context, Adler and Posner make the more modest claim that overall welfare is simply one morally relevant criterion - perhaps among several. This avoids many of the classic conundrums that utilitarians find themselves in, 
like the apparently welfare maximizing effect of "execut[ing] an innocent to appease a murderous mob" or "enact[ing] measures that benefit[] the superrich at the expense of the desperately poor" (Adler \& Posner 2006, p. 53).

In the second part of their argument, Adler and Posner posit that, even though CBA is not a direct measure of overall welfare, it provides a close enough proxy to be useful. They draw an important distinction here between a moral criterion and a decision procedure:

A moral criterion identifies the features of outcomes that make them morally better or worse than alternatives. A decision procedure is a technique for making choices, and the morally justified decision procedure is that procedure the employment of which leads to the best outcomes. (Adler \& Posner 2006, p. 62)

Under this typology, Adler and Posner view overall welfare as a moral criterion and $\mathrm{CBA}$ as merely a decision procedure. But because it is a decision procedure that tracks the moral criterion of overall welfare reasonably well, it is, according to Adler and Posner, a good (and "morally justified") decision procedure.

New Foundations represents the most ambitious and credible effort to date to build a solid theoretical defense of the use of CBA in evaluating government regulation. As we prepare to enter a new era of increased confidence in the legitimate role of regulation in society, it is a good time to examine these "new foundations." In the following pages, we offer our thoughts and impressions on this important book. Each of us approaches CBA with a heavy dose of skepticism, but each of us also approaches Adler's and Posner's book with a great deal of respect for the intellectual depth and rigor it has brought to the debate, and with a huge debt of gratitude for all that its authors have taught us.

We begin, in Part I, with a catalogue of New Foundations' virtues - its humility, its scrupulousness, its open-mindedness. We then go on to explore some of the philosophical thickets that threaten to engulf Adler's and Posner's theory. In Part II, we take on Adler's and Posner's claim that CBA, while not a direct measure of welfare, provides a proxy for that moral criterion that is close enough to use. We contend that this is ultimately an empirical claim that Adler's and Posner's thoroughly theoretical book does not support. Finally, in Part III, we take up the crucial topic of alternatives to CBA, arguing that the feasibility principle is more likely to track overall welfare than CBA because it focuses on factors that are important and avoids getting mired in fruitless attempts to quantify unquantifiable values. We also discuss the disconnect between the institutional role Adler and Posner envision for CBA - as a valuable tool for reining in and rationalizing over-zealous agencies - and the empirical evidence, which shows CBA consistently being used as a "one-way ratchet" - a tool to weaken regulation. ${ }^{1}$

\section{Crowded in the wings: The opportunity costs of CBA}

New Foundations contributes to a discussion on the merits of regulatory CBA that has been occurring at the intersection of economics, policy analysis, moral and political philosophy, and law. Any attempt to simultaneously draw from and inform multiple literatures in this manner runs the risk of oversimplifying and distorting, yet in New Foundations Adler and Posner have managed to operate at an extremely high level of sophistication in all of the frameworks that they deploy. This nuanced approach to the CBA debate has many virtues, which will be briefly explicated. It also has some vices, which will be enumerated with somewhat greater attention. 


\section{A. Old foundations}

To understand why Adler's and Posner's defense is in fact a novel one, it is important to recognize that many presentations of CBA are not as admirably restrained. Broadly speaking, regulatory CBA aims to provide a neutral and comprehensive method of evaluating policy proposals, a way of aligning the diverse consequences and values implicated by collective choices along a single quantitative metric. The framework therefore asks regulators to predict, weight, and aggregate policy impacts in order to identify options that maximize collective welfare, where "welfare" typically is defined and valued according to the weight that affected individuals themselves would be willing to place on an anticipated consequence (Arrow et al. 1996). Once relevant policy impacts have been estimated and monetized in this manner, regulators can, at least in theory, use CBA to select the point of marginal equivalence between social costs and benefits. Many economists and other commentators also believe that the application of CBA to a range of existing and proposed risk regulation programs can provide society with a basis for making optimal use of the entire regulatory budget that it devotes to risk prevention (Breyer 1993).

Obviously, the normative desirability of social welfare maximization depends on the attractiveness of the welfare criterion that is being maximized. On the standard CBA account, welfare is intended to be a capacious concept; it can include anything that is of significance to human wellbeing. However, welfare on the standard account must always be located within an individual citizen's welfare function (as opposed to some entity, such as a community or a nation, that expresses its aims and values through collective institutions and processes), and must always be converted in some fashion to a common and continuous quantitative metric (as opposed to some lexically ordered metric, such as those found within constitutions and other deontologically inflected laws, that treats certain rights or resources as inviolable). Thus, dominant presentations of CBA are premised on the implicit assumptions that welfarism provides the correct moral philosophy to guide public policy, that welfare is an individualistic and monistic concept, and that willingness-to-pay valuations correctly transform welfare impacts into monetary units for policy analysis.

\section{B. New foundations}

Recognizing how philosophically contingent and incomplete the standard welfare economic framework is, Adler and Posner wisely steer clear of it. They claim only that welfare "is part of the moral fabric of the universe, but.... do not insist that this fabric is exclusively welfare-woven" (Adler \& Posner 2006, p. 54). Likewise, they nowhere contend that individual willingness-to-pay valuations provide an ideal approximation of welfare, but instead acknowledge that numerous possible approaches exist and contend for normative superiority.

This approach has many virtues. For instance, Adler's and Posner's welfarism is not imperialistic. They are willing to admit the possibility that deontological trumps, notions of desert and responsibility, and other non-welfarist considerations can also figure into policymaking. Nor is their welfarism dogmatic. They recognize that plausible arguments exist to support a variety of different currencies of wellbeing, including expressed or revealed preferences à la most welfare economists, an objective list approach à la Amartya Sen and Martha Nussbaum, a hedonic approach à la Jeremy Bentham, and so on. They ultimately settle on a laundered preferentialist approach (about which more below), but 
they are careful to acknowledge that theirs is only one approach to the definition and estimation of wellbeing.

Adler's and Posner's welfarism also is not sloppy. Occasionally, one encounters welfarists who refuse ever to specify what valuation metric they are using. In the extreme this refusal can mean that their work consists only of elaborate tautologies (Kaplow \& Shavell 2002; Coleman 2003). One also sometimes encounters welfarists who appear to pick and choose among valuation metrics in order to respond to various objections and criticisms, often without adequate disclosure that this opportunistic selection is going on. New Foundations does not exhibit these ills. It is specific and scrupulous throughout. When the authors do remain agnostic on particular issues, they do so only because they believe that the issue is orthogonal to their present inquiry, not because they are trying to duck or deceive.

Finally, Adler's and Posner's welfarism is not insensate. They are not utilitarians who simply wish to maximize overall wellbeing irrespective of where it happens to roost (Sen 1970a, p. 22) or, worse yet, willingness-to-pay fetishists who would maximize monetized wealth even to the point of extinguishing the very human lives that will supposedly be "better off" on account of the accumulated wealth (Kysar 2007). Instead, Adler and Posner (2006) take the moral challenge of establishing a value criterion quite seriously, and they wisely shun pure willingness-to-pay or pure utilitarian approaches, which they describe as "problematic intellectual ballast ... to which CBA has long been tied" (pp. 7-8).

\section{New challenges}

As noted above, Adler and Posner (2006) advocate what they term "a restricted, preferencebased account of welfare" in order to implement the goal of maximizing overall wellbeing. On this approach, regulators should value policy consequences according to individual preferences, so long as (i) an individual actually has the preference, (ii) the preference survives idealization, and (iii) the preference is self-interested (pp. 35-37). Thus, in sharp contrast to conventional CBA approaches, which Adler and Posner (2006) rightly note are grounded in "an implicit commitment to the view that people's unrestricted preferences should be respected" (p. 19), the authors advocate laundering unrestricted preferences such that the basis for policymaking ends up reflecting only preferences that impact personal wellbeing (rather than altruistic or other-regarding preferences such as environmental existence values), and only idealizable preferences (rather than drug addiction, racial prejudice, or other objectively bad preferences). In this manner, preferences count for policymaking only if they are "sufficiently well-informed, authentic, deliberative, and otherwise ideal to constitute a welfare improvement" (Adler \& Posner 2006, p. 19).

Notwithstanding its admirable intellectual spirit, this approach raises an obvious question: Why do Adler and Posner advocate trimming out only preferences that fail idealization, rather than also adding in ideal preferences that the well-informed citizen should have, but for whatever reason she lacks in the real world? That is, having taken the critical first step away from welfare economics' deep commitment to preferentialism, why not go further in the direction of an objective list of resources, goods, or virtues as the best proxy for overall wellbeing, since the authors have conceded that the individual is not always the best judge of her own wellbeing? (Adler 2004). Adler and Posner might respond that individuals would not experience a welfare gain from objectively good outcomes that they do not, in fact, prefer. But that objection assumes the very primacy of preferentialism that has been put into question. In fact, preferences cannot be objectively 
identified by policy analysts any more than a list of perfectionist virtues could be (Sagoff 2004; Kelman 2005). Accordingly, Adler's and Posner's decision to remain rooted in a preferentialist account of welfare has the feel of an uneasy compromise.

Partial idealization of preferences also invites analytical complications. For instance, when the authors describe problematic categories of preferences - preferences that they think need to be laundered out of the welfare calculus - they describe altruism and sadism as separate categories. But if one were operating from a baseline of unrestricted preferentialism in the fashion of most welfare economists, then one might simply lump altruism and sadism together into a single category of other-regarding preferences: Regardless of whether one prefers another to experience pleasure or pain, the theoretical challenge for welfarism arises from the fact that the preferrer makes her preference contingent on the welfare impacts of another (Sen 1970b).

Described this way, altruism and sadism appear to be preference categories that should be treated (and screened out) together. By instead discussing them separately, Adler and Posner seem to implicitly concede a more Aristotelian conception of value, in which altruism is perhaps screened out because of problems of double-counting or some other pragmatic concern, but sadism is screened out simply because it is not virtuous, because it is morally objectionable. ${ }^{2}$ Again, the question is raised, why not more affirmatively and comprehensively embrace an objectivist approach to the definition and accounting of welfare?

\section{Old challenges}

In addition to its philosophical defense of CBA as a decision procedure with indirect moral significance, New Foundations also seeks to account for CBA as a tool of intergovernmental control (Posner 2001). From the first perspective, the important question is whether CBA adequately tracks overall wellbeing (a question addressed below in Part II). From the second perspective, the question is whether CBA is defensible in light of its overall role and impact within a political system. The fact that both of these perspectives are deployed in New Foundations means that Adler and Posner must take on challenges that no single book, no single author, and not even a dynamic duo of authors, could adequately address.

Unfortunately, the political economy track of New Foundations does not bear the same level of intellectual care and catholicity as the moral philosophy track. Indeed, in sharp contrast to their steadfast efforts to remain non-dogmatic with respect to moral philosophy, the authors reveal a rather partisan worldview from the perspective of political economy. For instance, when discussing how the preference laundering exercise should be undertaken, Adler and Posner state that "for institutional reasons," it should probably be conducted or supervised in the US by "the personnel of the OMB [Office of Management and Budget]" (Adler \& Posner 2006, p. 150). This assignment is selected with little consideration of alternatives or of arguments for or against the role of OMB in US policymaking. Instead, in its political economy sections, New Foundations simply presents $\mathrm{CBA}$ as a method by which the executive keeps a tight rein on regulatory agencies, making them accountable to the president who is, in turn, believed to be accountable to the people. Agencies are the villains in this tale, filled with "badly motivated administrators" and "well-motivated but fallible ones" (Adler \& Posner 2006, p. 98) who seem to oscillate between being self-aggrandizing regulatory zealots or hapless victims of industry capture. 
This picture begs to be complicated. A fruitful approach would pursue an alternative that Adler and Posner (2006) themselves raise in New Foundations, but quickly abandon. At one point, they somewhat incredulously refer to the "interesting possibility" that "the president and the OMB are captured by industry while the agencies themselves are not" (p. 121). To many observers, this alternative is not just an interesting possibility, but an obvious and disastrous reality. Indeed, everything that has been learned about the intimidation and abuse of scientists and career civil servants at EPA and the Department of the Interior during the last several years bears that impression out (Doremus 2005, 2008). From this perspective, the authors' uncritical assignment of preference-laundering responsibility to the OMB appears insufficiently cynical. Whatever its status in moral philosophy, regulatory CBA in lived political experience is inseparable from institutional and political economic questions regarding the proper locus of regulatory control. The OMB's role from this perspective cannot simply be equated with presidential - and therefore democratic - accountability.

Throughout a recent US Environmental Protection Agency (EPA) rulemaking, for instance, one can read between the lines a sense of frustration among EPA staff members regarding the executive's demand that the agency generate quantitative and monetary estimates of regulatory impacts at the same time that the OMB was refusing to grant the agency required approvals to conduct original valuation studies (Kysar 2009b). Because CBA requires the generation of enormous amounts of empirical and monetary data in order to operate anything like a reliable proxy for overall wellbeing, the ability to assign and manipulate the burden of proof in policymaking settings therefore becomes crucial. OMB's ability to demand the use of CBA while simultaneously denying authorization to develop the empirical record to fulfill its reliable use meant that CBA became a device for watering down Congress's clearly stated requirements in the Clean Water Act.

Interagency dynamics such as these must be appreciated in order to properly evaluate legal academic arguments, such as Adler's and Posner's, that attempt to defend regulatory CBA as an instrument of accountability. Regulatory CBA does not serve democratic accountability in the abstract; rather, it serves accountability to particular officials and particular institutions that may or may not partake of democratic legitimacy themselves. In the US, CBA in practice has tended to serve agency accountability to the president, even as against the contrary wishes of Congress. Indeed, Congress has only rarely endorsed CBA in the environmental, health, and safety laws that it has passed. Thus, the institutional and political economic arguments offered by Adler and Posner in favor of CBA must be understood in the context of the larger debate over executive power that has been brought to the fore during the most recent Bush Administration. To simply equate agency accountability to the president with democratic accountability is to adopt a particular and controversial theory of the constitutional separation of powers (Calabresi \& Rhodes 1992; Lessig \& Sunstein 1994; Froomkin 1994; Percival 2001; Bressman \& Vandenbergh 2006; Symposium 2008).

\section{E. Challenges yet to come}

For dimly understood reasons, optimific frameworks such as welfarism have a tendency to crowd out competing frameworks, even when practiced by theorists with the rigor and humility of Adler and Posner. To give just one example, when Adler and Posner discuss the incommensurability objection to CBA - that is, the objection that reducing all values to a single monistic language of utility or welfare works over time to actually reconstitute 
what we care about in a different and lesser form - they do so largely by asking whether this process would cause "negative psychological impacts" or "make people upset" (Adler \& Posner 2006, p. 164). Such emotive consequences are, of course, distinctively welfarist impacts of the decision to abandon incommensurability; accordingly, to focus on these impacts as the relevant criteria for deciding whether incommensurability is a serious concern is, in a sense, to deny the very existence of the concern.

Adler and Posner offer a variety of additional arguments against the incommensurability concern, but they tend to be primarily interested in whether the idea of incommensurability makes sense from within a welfarist framework. Naturally, the answer is no: "We think it implausible that ecosystem destruction, the loss of an endangered species, or other forms of environmental degradation would have a welfare impact on an ordinary individual so substantial that no amount of money could repair the welfare loss to her" (Adler \& Posner 2006, p. 159).

Adler and Posner want to carve out a separate place for welfarist determination of the content of law and policy. They do not wish to deny the existence or seriousness of non-consequentialist factors like incommensurability; they just want to cabin them so that welfarist and non-welfarist frameworks can peacefully coexist. ${ }^{3}$ The problem with this approach is that laws never merely reflect preferences, but also help to produce them. Law plays a role in endogenously constituting the categories with which we view and value the world. Thus, to embrace and express a position of commensurability within our environmental, health, and safety laws may not simply be a concession to practicality or to a limited role for welfarism. It may instead be the commencement of a process of cultural change that eventually allows welfarism to become the hegemonic lens that Adler and Posner expressly disavow. ${ }^{4}$

Indeed, the authors themselves appear to slip down that slope at various points in New Foundations, such as when they defend the use of a monetized value of human life for regulatory CBA on the theory that " $\mathrm{t}]$ here are numerous contexts, other than CBA, in which premature death or the risk of premature death is priced" (Adler \& Posner 2006, p. 178). The examples they provide, such as damages awards in tort suits, are all contexts in which a wrongful death is being compensated for ex post; none of the examples concerns an ex ante decision to allow a premature death to occur, as CBA does (Heinzerling 2000, 2006).

This concern is related to a larger, and final, point about the potential role of CBA within contemporary legal culture, even the more modest and non-dogmatic form of CBA offered by Adler and Posner. As noted above, New Foundations is careful to accept the importance and viability of non-welfarist inputs into policymaking. However, the book's attention is otherwise exclusively focused on developing the best version of welfarism that the authors can muster. Moreover, there are moments when the authors suggest that the outputs of welfare calculation should dominate policymaking, even if they do not go so far as to say that it should completely occupy it, as other welfarists have. This impression of welfarism's dominance is most dramatically revealed in New Foundations by the authors' statements that "overall welfare is the baseline goal of agencies" (Adler \& Posner 2006, p. 102) and that relevant deontological trumps are "more or less" already captured in the constitution (Adler \& Posner 2006, p. 157).

If the important deontological considerations are to be found in the constitution, then we cannot really understand the Endangered Species Act, the Marine Mammal Protection Act, the National Environmental Policy Act, the Wilderness Act, and numerous 
other legislative steps to cordon off certain natural resources from the market's - and by extension welfarism's - demand that their worth constantly be demonstrated in order to avoid being transformed into just another factor of production. More dramatically, one could argue that modern environmental law has been centrally concerned with examining and redefining the relationships that exist between the political community and various "others" of environmental law, such as future generations, members of foreign nations, and non-human life forms (Kysar 2009a). These populations are both vulnerable to environmental harm and disabled from participating in the political communities that, in large part, determine their fate. They are not included within the orbit of constitutional rights that Adler and Posner suggest exhausts the relevancy of deontology to law. Yet they also are not addressed by regulatory CBA, since their status must be determined by judgments that are analytically and morally prior to CBA.

CBA produces especial controversy in the environmental context because the parameters typically excluded from analysis under CBA - those matters that are taken as given or otherwise ignored in the analysis - are the same parameters that many observers believe to constitute environmental law's raison d'être. CBA can reveal what is welfaremaximizing only because certain critical judgments regarding whose welfare, valued according to what standards and procedures, have been taken off the table. Thus, when Adler and Posner (2006) state that "a virtue of CBA is that it reduces moral considerations to an algorithm that requires no, or little, moral judgment" (p. 135), they actually identify as a virtue what critics regard as the methodology's chief vice. To critics, the use of CBA to implement environmental, health, and safety laws often appears to be an attempt to truncate the scope of those laws, excluding from view certain questions and possibilities that do not fit within the individualistic, preferentialist, and outcome-oriented algorithm of CBA.

For example, CBA as conventionally practiced in the regulatory context: (1) cannot determine safe minimum standards in relation to particular natural resources or ecosystem services, since its welfarist framework adopts the Grundnormen that all values are commensurable and that all resources substitutable (Bishop 1978; Howarth 1995; Randall \& Farmer 1995); (2) cannot fix a society's obligations to foreign citizens or non-human species, since those questions demand an analytically prior determination of whether, and on what basis, such entities "count" within the cost-benefit community (Trumbull 1990; Freeman 1993); and (3) cannot clarify a society's obligations to future generations, since its method of translating future costs and benefits into present values implicitly prejudges the very questions of distributive equity and environmental sustainability under consideration (Norgaard \& Howarth 1991, p. 177; Cowen \& Parfit 1992; Page 1997; Kysar 2007).

Nor are these the only areas of environmental law in which regulatory CBA is incomplete. The method also: (4) provides an inadequate framework for contemplating catastrophic potentialities such as those associated with climate change, since the methodology assumes a smooth linear world in which median expectation values provide reliable decision criteria (Weitzman 2007); (5) provides little guidance on whether to reallocate burdens of proof or design other policy methods for managing informational uncertainty, since CBA depends on the assumption that adequate information for calculation either already exists or can be generated through methods that are separate from the policy judgment itself (Loasby 1999); and, finally, (6) cannot accommodate law's affirmative role in redefining rights and in influencing preferences, since the methods of 
valuation typically deployed in welfare economics infer costs and benefits against the existing backdrop of rights and preferences (Tribe 1974; Norton et al. 1998).

When CBA is used to implement laws aimed at these kinds of questions, the methodology ends up treating that which should be outcome determining as instead outcome determined. For instance, the Endangered Species Act as construed in TVA v. Hill (1978), and the Clean Air Act as construed in Whitman v. American Trucking Associations, Inc., (2001) would be incomprehensible from the perspective of CBA, since the statutes are aimed at changing the legal foundation of existing ordering, rather than at conforming law to the predilections of the status quo.

Again, Adler and Posner seem to protect themselves against these kinds of objections by emphasizing that their welfarism can be supplemented by other considerations when fashioning law and policy. But to draw a lesson from economics, there are significant opportunity costs to the effort to fine-tune CBA and other applied welfarist techniques, when the moral and political questions just mentioned remain a mere sideshow. For instance, at one point in New Foundations, Adler and Posner (2006) advocate the hiring of more economists by government to improve "agency culture" (p. 189), but the cultural deficit to be remedied arguably requires individuals who are better schooled in the plurality of values, rather than in the value monism of welfare economics. Elsewhere Adler and Posner (2006) wish for "perfect welfarist measurement" in which every policy impact would reflect the "disaggregated" value of individual lives (p. 181), but arguably we should be thinking more about those life forms that do not even register as interestholders in our current welfarist framework. Finally, the authors suggest that individuals should be made to participate in contingent valuation studies as a "civic duty" (Adler \& Posner 2006, p. 166), even if the valuation framework is offensive to them, when arguably we should be asking for far greater sacrifices from each other than merely accepting the treatment of environmental protection as a trip to the shopping mall.

In short, we hope that, having shown that CBA can play only an incomplete role in the formation of law and policy, Adler and Posner now will devote their considerable talents and ingenuity to the sideshows, the questions that loom offstage and that cannot be resolved by or even posed within the language of welfarism, but that are growing in urgency nonetheless.

\section{Coming down to earth: The impracticality of CBA}

Adler's and Posner's defense of CBA is grounded in more than just their thoughtful and painstakingly developed defense of a limited account of welfarism. They also argue that $\mathrm{CBA}$ is the best way to estimate and weigh the welfare effects of any potential policy decision. They do not contend that CBA can provide a direct measure of overall welfare, but rather that CBA provides a proxy that is close enough to be useful. In making this claim, however, Adler and Posner (2006) fail to fully appreciate one of the central insights of the book: just because a decision procedure tracks overall welfare in theory, we cannot assume it will necessarily do so in practice (p. 69).

Once they have explained the distinction between a moral criterion (like welfarism) and a decision procedure (like CBA), Adler and Posner pose a rhetorical question: Why settle for a decision procedure like CBA that is no more than an imperfect proxy for the thing we really care about? Why not simply craft a decision procedure that directly implements overall welfare? They dub this hypothetical decision procedure "direct imple- 
mentation.” Then they answer their question by pointing to the mismatch between theory and practice. While moral criteria operate in the world of theory, decision procedures must be able to deal with the hurly burly of the real world. So, Adler and Posner tell us, even though in theory direct implementation would track overall welfare perfectly, in practice it would fail miserably. Direct implementation would be far too expensive and time consuming to be feasible. Moreover, it is so complicated that it would be hopelessly non-transparent to all but the technically trained. As such, it would be very difficult to monitor and accordingly vulnerable to political manipulation and corruption. For all these reasons and others, direct implementation as a decision procedure strays very far from the criterion of overall welfare that it was designed to track in the first place.

Does this sound familiar? These are exactly the complaints about CBA as a decision procedure that many of us have been voicing for years. The problem is that, while their defense of overall welfare as a morally relevant criterion and their description of CBA as an imperfect proxy for overall welfare are thoroughly, painstakingly, and convincingly argued, Adler and Posner have failed to demonstrate that CBA as a decision procedure does not suffer from all the same shortcomings they associate with direct implementation: inaccuracy, vulnerability to manipulation, and inordinate expense.

\section{A. Inaccuracy}

Although in theory CBA seems like it should roughly track overall welfare, will the results it produces in practice track welfare accurately enough to provide meaningful information? To their credit, Adler and Posner acknowledge many of the problems with CBA that make it an imperfect proxy for overall welfare. But, because they defend it as a decision procedure rather than a moral criterion, they have an easy out. In response to the problems of wealth effects, the endowment effect, imperfect information, discount rates, and other problems that have always plagued CBA, they can simply say: We never said it was perfect; it's just a rough and ready decision procedure!

But just how imperfect is it? If it is just a little bit imperfect, as Adler and Posner suggest, then maybe it's good enough for government work. But if the various imperfections result in large disparities between CBA and overall welfare, then it may actually serve to mislead rather than enlighten decision-makers. As Adler and Posner (2006) acknowledge on the final page of the book, this is "at bottom an empirical question" (p. 190). Yet because New Foundations stays primarily at a theoretical level, it never answers the crucial question of whether CBA's various well-known infirmities - imperfect information, the endowment effect, discount rates, and wealth effects, to name a few - will, in practice, cause disparities between CBA and overall welfare that are simply negligible and best ignored, or large enough to distort outcomes.

\section{Imperfect information}

One of the biggest problems that hampers the accuracy of CBA is that we simply do not have the data, nor indeed the basic understanding of many of the physiological and environmental processes that affect human welfare, to quantify many aspects of welfare. Adler and Posner (2006) are certainly aware of the problem. Indeed, they concede that "CBA analysts, in practice, ignore welfare dimensions [that] are just too hard to estimate given current techniques - for example, fear or friendship" (p. 78). They are right that certain aspects of welfare are routinely left out of CBA because they cannot be measured or quantified. But "fear and friendship" are the least of its problems. 
CBAs of environmental regulations inevitably leave out whole categories of benefits because relevant data are simply unavailable. One study looked at 25 CBAs of agency rules reviewed by OMB in a one-year period and found that in 19 of the 25 cases, the agencies were unable to monetize any of the rules' benefits. In the remaining cases, significant benefits were omitted (Driesen 2006; Hahn \& Dudley 2007). The National Highway Traffic Safety Administration's 2006 CBA of its new rule setting fuel efficiency standards for light trucks omitted the climate change impacts of the rule entirely (US Department of Transportation 2006). The EPA's CBA of its rule regulating cooling water intake structures at power plants left out $98.2 \%$ of the fish that would be saved. ${ }^{5}$ And the EPA's CBA of its Mobile Source Air Toxics Rule left out literally all of the benefits at which the rule was aimed; that is, those associated with reductions in air toxics. ${ }^{6}$

Because the benefits of regulation are so often harder to quantify than the costs, these omissions lead CBAs to be systematically biased against regulation. Moreover, because we so often lack the data or scientific understandings necessary to make definitive noncontroversial estimates of benefits, CBA is plagued by indeterminacy of enormous proportions. A study by Cass Sunstein of the EPA's CBA for its regulation of arsenic in drinking water, for example, found that while the EPA estimated the costs of that rule at around $\$ 210$ million, reasonable people making reasonable assumptions might peg the benefits of the rule anywhere between a low of $\$ 13$ million or a high of $\$ 789$ million (Sunstein 2002a; Sinden 2004). This extreme level of indeterminacy means that the outcome of a CBA can always be contested and that agency personnel can always manipulate the numbers to reach a politically motivated result. The CBA that accompanied the EPA's proposed mercury rule for power plant emissions, for example, initially found benefits of $\$ 15$ billion to $\$ 73$ billion and costs of just $\$ 2$ billion to $\$ 5$ billion (Heinzerling \& Steinzor 2004). When the proposed rule produced a public outcry for being too lenient, the EPA responded not by changing the rule, but by adjusting the CBA. This time the CBA found net costs of $\$ 850$ million, rather than the tens of billions of net benefits it had found in connection with the proposed rule. ${ }^{7}$

CBA may seem to track overall welfare reasonably well in theory. However, when the inadequacy of information leads to indeterminacy of this magnitude, we have to ask whether CBA produces useful or even meaningful results.

\section{Wealth effects}

Because CBA attempts to measure welfare in terms of dollars, it suffers from a longrecognized infirmity, the problem of "wealth effects" (Adler \& Posner 2006, pp. 72-73). Stated simply, this problem arises from the fact that an additional dollar is generally worth more to a poor person than to a rich person. A project that causes a large welfare loss to a community of poor people may therefore be toted up by CBA as less of a dollar loss than a similar project that causes a relatively small welfare loss to a community of rich people (Adler \& Posner 2006, p. 142).

Adler and Posner (2006) are well aware that this problem can cause the results of CBA to diverge significantly from overall welfare maximization. Initially, they suggest that the problem can be solved by adjusting the preferences of the rich and poor through the use of distributive weights. Thus, an individual's preferences would be multiplied by some factor inverse to her wealth (p. 73) However, this raises a whole host of difficulties, and while economists have tried hard to resolve them, there is still no agreed upon method for imposing distributive weights (p. 152). ${ }^{8}$ 
Ultimately, Adler and Posner (2006) conclude that "the more practicable course" is for agencies to forego the minefield of distributive weighting and instead simply "avoid projects where the distribution of wealth among project winners and losers is substantially different" (p. 152). They present this as a moderate and unobjectionable proposal. The implied assumption is that the status quo is neutral and that when government refrains from acting, it can do no harm. In fact, however, this seemingly modest proposal would have far-reaching implications. If government really adopted a policy of avoiding projects (or regulations) where the distribution of wealth among project winners and losers differed substantially, there would be no corrective action in all sorts of situations in which the burdens of industrialization have fallen disproportionately on the poor. This would mean, for example, taking no steps to reduce pernicious levels of lead and particulate matter, which tend to concentrate in inner city areas. If implemented on the international level, presumably this approach would also require governments to turn a blind eye to climate change, since such regulation will inevitably impose the largest costs on the richest and most carbon-intensive countries in the world, while conferring a large share of benefits on some of the poorest countries in the world.

\section{The endowment effect}

Another well-known problem with CBA is the endowment effect. The CBA analyst measures the costs and benefits of a project by adding up the "compensating variations" ("CVs") associated with each individual affected by the project. An individual's CV is the amount of money one would need to either give to or take from her if the project were implemented in order to make her equally as well off as she would have been in the status quo. The problem is that, for reasons that are not entirely understood, experiments repeatedly show that the amount of money people are willing to pay to get something they do not have is consistently lower than the amount they are willing to accept to give up something they have (Horowitz \& McConnell 2002). This means that particular goods do not have stable CVs. An individual's CV for a particular good will vary depending on whether it is something she previously had that is being taken away, or something she does not have but stands to gain. This creates an inherent indeterminacy in CBA that has been dubbed "the endowment effect."

Adler and Posner (2006) are, of course, well aware of the endowment effect. They acknowledge that it produces indeterminacy in CBA (p. 168), but they quickly brush off the problem. "The fact that CBA might produce an indeterminate result is not a serious problem for CBA," they tell us, "as long as this occurs seldom" (Adler \& Posner 2006, p. 169). Once again, the fundamentally empirical nature of the inquiry rears its head. But rather than simply acknowledging that the question is an empirical one that is beyond the scope of their decidedly theoretical book, Adler and Posner answer the question they have posed with a hypothetical. In what comes off as a bit of a non sequitur, they ask us to imagine that $90 \%$ of CBAs are determinate and accurate. They then observe that, if this were true, CBA would be a good procedure. After delivering that unhelpful tautology, they take refuge again in theory. "Considerable theoretical work," they tell us, "suggests that, if preferences are well-behaved, the difference between an individual's willingness to pay (WTP) and willingness to accept (WTA) amounts for a given project will usually be small” (Adler \& Posner 2006, p. 169).

Finally, when Adler and Posner (2006) do look at the empirical literature, they concede that it "often show $[\mathrm{s}]$ a much larger WTP/WTA disparity" than the theoretical 
literature predicts (p. 169). In other disciplines, when the experimental data do not support the hypothesis, the response is to throw out the hypothesis. Not so here. Adler and Posner throw out the experimental data instead. The large WTP/WTA disparity is a result of "strategic behavior" rather than legitimate preferences, Adler and Posner tell us. The solution is for the CBA analyst to "launder" preferences of these "distortions" before using them. They offer few guidelines for the analyst engaged in the delicate and perhaps presumptuous task of deciding which preferences to retain as "true" and which to launder out as "distorted." But this is no doubt a dangerous business that strips the concept of preferences of one of its most appealing characteristics - its democratic nature - and makes CBA vulnerable to charges of elitism.

Ultimately, it is hard to be sanguine about the large WTP/WTA disparities that consistently show up in the experimental data. Indeed, WTA amounts are often five to ten times higher than WTP amounts (Knetsch 1990). This has the capacity to create significant indeterminacy in CBA. Moreover, since WTP is more often than not the measure used in quantifying environmental values, this is another source of indeterminancy (Knetsch 1990).

\section{Discounting}

Discounting is another big source of indeterminacy for CBA. Everyone agrees that dollars should be discounted, because interest rates and inflation clearly make a dollar tomorrow less valuable than a dollar today. But when it comes to things that are less clearly translatable into dollar terms - like human lives, or ecological values - it is much less clear what discount rate should be attached to future gains and losses, or, indeed, whether any discount rate should apply at all (Revesz 1999).

Here, Adler and Posner simply punt. They acknowledge that the choice of discount rate has a dramatic effect on outcomes. In fact, they provide an elegant chart that shows how over a 100-year period the difference between applying no discount rate (an approach to environmental values advocated by a number of prominent scholars [Heinzerling 1999; Revesz 1999]) versus a 7\% discount rate (the approach advocated by the OMB [Office of Management and Budget 2003]) yields a disparity of \$5 million versus $\$ 5,000$. So, unless we can agree on an appropriate discount rate, this source of indeterminacy clearly matters a lot. Yet, even though Adler and Posner (2006) acknowledge that the choice of discount rate remains "hotly contested" (p. 173), "with no definitive resolution in sight," they insist that this "in no way undercuts [their] basic argument ... for CBA as a welfarist decision procedure” (p. 174).

Do they perhaps protest too much? Adler and Posner offer no solution - no single defensible approach to discount rates. But without a resolution, the problem of discount rates continues to cause significant indeterminacy and endless contestability in CBA, thereby seriously undercutting their argument.

But that's only part of the story. The big problem with discounting is that, over long time spans, any discount rate devalues the lives of future generations vis-à-vis present generations. Adler and Posner try to sidestep this problem by telling us again that CBA is not perfect. It is not a super-procedure. It does not take into account all factors that may be relevant to a decision. Distributional equity is a separate problem for which we should devise a separate decision procedure, they say.

This time, however, the "CBA's-not-perfect" excuse is particularly ineffective. When it comes to discount rates, it is not just that CBA ignores issues of distributional equity, it 
creates them. CBA exacerbates distributional inequity between current and future generations by making it look like less harm is occurring to future generations than actually is. So it is not just that CBA leaves something out that can be accounted for through a separate procedure. Discounting actually distorts the outcome of CBA. This is one of many ways that CBA obscures relevant issues rather than making them more transparent.

\section{B. Vulnerability to manipulation}

In cataloging the reasons why direct implementation of overall welfare would make such a bad decision procedure, Adler and Posner (2006) tell us, among other things, that "Congress, the president, other oversight bodies, and citizens would find it difficult to monitor official compliance with the direct implementation procedure" because it would be so complicated and difficult to understand. This would "effectively grant wide discretion to implementing officials" and "badly motivated officials would use this discretion to advance their own interests" (p. 67). This is precisely the problem with CBA. All of the difficulties that Adler and Posner acknowledge - imperfect information, wealth effects, the endowment effect, contested discount rates - make CBA ultimately indeterminate and therefore endlessly contestable and manipulable in a way that invites political corruption (Sinden 2005).

In Chapter 4, Adler and Posner (2006) consider these issues - the problem of "badly motivated" agency officials and whether CBA might be subject to manipulation for political ends. They invoke game theory to make an argument that CBA is a good decision procedure even in the face of such pressures, but the argument is ultimately tautological. They construct a model that is built on a set of assumptions that pre-ordain the conclusion. They ask us to assume that CBA is "costless and perfectly accurate" (p. 107), and "to imagine that it converts a relationship of asymmetric information to one of full information" (p. 104). Based on these assumptions, they construct a model that demonstrates that when agencies perform CBA, regulatory outcomes will be closer to optimal than when they do not (pp. 103-108). It is a conclusion that is hard to argue with. If it were in fact true that CBA provided information that accurately tracked overall welfare in a costless and transparent way, then it probably would be less subject to manipulation and political corruption than many other decision procedures. Most people probably do not need game theory to convince them of that.

Adler and Posner (2006) acknowledge that if, contrary to the assumptions in their model, CBA is actually expensive and inaccurate, "then it may not be desirable for agencies to engage in" (p. 109). So the big question is whether CBA does in fact, in the real world, provide meaningfully accurate information in a transparent way. As Adler and Posner acknowledge, these are ultimately empirical questions and therefore questions that their theoretical book fails to answer. As discussed above, there is good reason to suspect that a whole host of infirmities - inadequate information, wealth effects, the endowment effect, and discount rates - compromise the accuracy of CBA to a significant degree. As for transparency, Adler and Posner acknowledge in the context of direct implementation, that regardless of the quality of the information produced, when a procedure is too complicated and sophisticated, it may produce results that lay people cannot follow or replicate, and in this way reduce transparency. That is exactly the case with CBA, which inevitably involves a host of complicated and inaccessible concepts, like discount rates and contingent valuation. Adler and Posner assert repeatedly throughout 
the book that CBA enhances transparency, but they never really back the claim up or respond to the numerous authors who have shown the opposite to be true (Sinden 2004).

\section{Inordinate expense}

Another problem that Adler and Posner identify with direct implementation of overall welfare but brush aside when it comes to CBA is the time and expense involved in doing it. They maintain that direct implementation would be too expensive and time consuming to be practical, but although they acknowledge that CBA is also expensive, they argue that it is less so. They cite a study by Richard Morgenstern and Marc Landy that indicated that CBAs cost on average $\$ 1$ million to $\$ 2$ million (Adler \& Posner 2006, p. 80), and conclude that, at least where regulations are major, CBA is worth it.

The problem is, by the time one finishes New Foundations, one is hard pressed to imagine that if Adler and Posner were to look carefully at the CBAs that formed the basis for the Morgenstern study, they would find them up to snuff. By the time Adler and Posner are done honestly acknowledging all the ways in which CBA departs from welfare and coming up with ways to account for these difficulties, they have made CBA even more cumbersome, expensive, and time consuming than it was to begin with. Now, on top of all the other difficulties inherent in calculating the costs and benefits of regulations, CBA analysts also have to (1) launder preferences to eliminate non-ideal and disinterested preferences (Adler \& Posner 2006, p. 72), as well as preferences attributed to the "distortions" of the endowment effect (Adler \& Posner 2006, pp. 170-171); (2) possibly weight preferences to account for wealth effects (Adler \& Posner 2006, pp. 72-73); and (3) use heterogeneous values of statistical lives to reflect the fact that "not every premature death has the same impact on overall welfare" (Adler \& Posner 2006, p. 182), just to name a few.

Although Adler's and Posner's theoretical arguments are very well-crafted, the mystery is why they chose to take the next step and take a position on whether CBA is an effective decision procedure in the real world. This is, as they acknowledge, ultimately an empirical question that is beyond the scope of their theoretical book.

\section{Sizing up the competition: The feasibility alternative}

One of the strengths of New Foundations is its recognition that alternative decision procedures exist and that the proper question is whether CBA is better or worse than alternative procedures.

One such alternative is feasibility analysis (Driesen 2005), which focuses on the relationship between costs and facility finances in order to predict when the costs of environmental regulations might cause widespread plant shutdowns (Driesen 2005). Regulators can use feasibility analysis to avoid concentrating costs on workers through such consequences, but also to recognize when they can regulate pollution with serious health and environmental effects aggressively without serious economic disruption (Driesen 2005).

Adler and Posner (2006) employ a typology to argue that CBA likely tracks overall wellbeing better than the alternatives. This typology divides procedures into wide welfarist procedures, narrow welfarist procedures, and non-welfarist procedures (p. 74). By characterizing CBA as a complete welfarist procedure and feasibility analysis as a nonwelfarist procedure (pp. 75, 78) they make it appear likely that CBA tracks overall wellbeing better than feasibility analysis. Both CBA and feasibility analysis, however, are more accurately viewed as narrow welfarist procedures, albeit with differing foci. 
CBA focuses on those aspects of welfare that prove amenable to quantification. This excludes many, probably most, environmental health effects and nearly all ecological effects. ${ }^{9}$ Many of the non-quantifiable benefits CBA neglects are clearly significant. For example, the possibility that greenhouse gas emissions could trigger feedback loops that would raise average mean surface temperatures well above the temperatures in climate change models has played no role in CBA, for the simple reason that scientists cannot tell us how likely or unlikely this consequence is, or predict its magnitude. Recently, however, some economists have recognized that this potential catastrophe is a more important fact than the central benefits estimates of climate change models (Weitzman 2007), which have, in any event, so far underpredicted climate change. Focusing on the quantifiable produces a narrow welfarist procedure, not a broad one, because it leaves out significant environmental and health effects.

Adler's and Posner's (2006) response to this problem bears out their sophistication about economics and their neglect of science. In responding to Lisa Heinzerling's and Frank Ackerman's claim that many environmental benefits cannot be "quantified or priced," they emphasize the techniques available for pricing, but ignore the scientific problem of simply not having enough data to quantify a project's effects in non-dollar terms (pp. 162-163). This problem in quantitative risk assessment where it exists (i.e. in almost every case) makes carrying out the monetization step impossible, because quantification of effects (e.g. number of deaths) provides the number to be multiplied by the economist's estimate of a particular effect's dollar value. If the risk assessment number for a particular effect predicted by relevant science is zero, because the data are not there to come up with a number (e.g. climate change feedback loops), then you get zero as the result, no matter how completely you can monetize an array of hypothetical effects.

Feasibility analysis more comprehensively considers aspects of welfare that are central to environmental regulation, and should therefore be considered a procedure focused on welfare. Before regulators even apply a feasibility analysis they must decide whether a pollutant is likely to endanger public health or the environment. ${ }^{10}$ This broad regulatory trigger approach allows them to consider poorly characterized effects, which far too often turn out to be the most important ones. ${ }^{11}$ Thus, regulators committed to feasibility analysis, as it is practiced in our existing laws, consider the welfare benefits of regulation more completely than regulators distracted by CBA. Furthermore, an endangerment trigger encourages them to focus on significant health and environmental effects, which are likely to have more than a transient effect on overall wellbeing. When they get around to actually regulating, the fact that they cannot quantify the most important effects does not produce a major inaccuracy under a feasibility approach, because they are not required to quantify regulatory benefits. By contrast, an emphasis on quantified benefits distorts regulatory decision-making by leaving out very significant information about overall wellbeing, often the most significant information available.

A feasibility-based approach aims to maximize the reduction of pollutants. This maximization seeks to minimize serious potential consequences identified in the prior endangerment finding. These consequences include death and serious illness. Adler and Posner recognize that life and bodily integrity are essential components of welfare, and CBA likewise takes them into account, but to a much more limited extent.

However, the feasibility principle authorizes regulators to forego reductions when a measure would force the shutdown of a large number of plants (Driesen 2005). ${ }^{12}$ Feasibility analysis requires the consideration of cost (Adler \& Posner 2006, p. 79). ${ }^{13}$ For some 
reason Adler and Posner treat feasibility as a procedure not considering cost (p. 75), but every statute including such a criterion requires its consideration (McGarity 1983). ${ }^{14}$ If the costs make it likely that a proposed regulation would bankrupt a significant number of facilities, then the regulator presumptively should declare the level of regulatory control that renders this result infeasible (Driesen 2005). ${ }^{15}$

We can justify this attention to shutdowns in terms of a series of welfare relevant considerations that Adler and Posner (2006) use to explain their concept of overall wellbeing. They consider unrestricted preferences as telling us nothing of relevance to overall wellbeing, partially because people can desire that which does them no good (pp. 33-36). This implies that the dollar costs of regulation, since they represent both restricted and unrestricted preferences, have no necessary relationship to overall wellbeing. To correct for this, they require that only those preferences that survive idealization count (p. 36). This means, probably, that an objective observer would consider the preference as having some positive objective utility to the holder of the preference (pp. 50-52). In order to give us some idea of what such restricted preferences might look like, they draw on a list of desirable goods provided by Martha Nussbaum (see pp. 74-75). Eschewing plant closures serves several values on Nussbaum's list that CBA neglects. Plant closures often lead to firing workers, thereby ending their affiliation with colleagues and upsetting their position in society (p. 74). ${ }^{16} \mathrm{CBA}$ cannot quantify the value of affiliation, and the magnitude of costs cannot by itself tell you when costs will produce such an important disruption in people's lives; but a comparison of costs with the economic capabilities of firms, which feasibility analysis may demand, can warn us about a loss of affiliation (Driesen 2005). ${ }^{17}$ Furthermore, firing produces a sense of loss that constitutes an emotional loss, of the sort Nussbaum, and by extension, Adler and Posner recognize as an important welfare loss (p. 75). ${ }^{18}$ Furthermore, loss of employment in some contexts gives one a feeling of a loss of control over one's environment, another component of welfare neglected by CBA (Adler \& Posner 2006, p. 121). ${ }^{19}$ In a stable employment situation, an employee can feel she has some influence on the work environment. Hard work and sensible interaction can lead to advancement or at least preservation of one's place. Imposition of an infeasible regulation can create a welfare loss, in the form of a loss of that control. None of this is quantifiable; all of it is implicitly recognized in the feasibility principle's protectionism.

Estimates of the overall magnitude of regulatory costs, however, tell us nothing about employment consequences. Imposition of high cost regulation on robust firms can lead to an increase in employment and corresponding welfare gains, as polluters hire workers to control pollution (Goodstein 1999). ${ }^{20}$ Small costs imposed on marginal facilities can make them go under. CBA forces regulators to spend inordinate amounts of time quantifying benefits, quite unreliably, thereby making it harder to carefully consider the important dimensions of costs. Feasibility analysis, by contrast, considers only laundered preferences, those cost impact preferences that survive idealization.

Thus, both CBA and feasibility analysis constitute narrow welfare-based "procedures." Feasibility analysis, however, is more likely to track overall wellbeing, as it focuses on factors that are important and survive idealization.

A significant weakness of New Foundations involves its failure to acknowledge that, unlike what feasibility analysis is likely to support, CBA has been consistently employed as a tool to weaken regulation, with little regard for regulation's impact on overall wellbeing (Bagley \& Revesz 2006). ${ }^{21}$ Acknowledging this fact would not destroy the case for $\mathrm{CBA}$ and would lead to a more fruitful dialogue about how much of its poor track 
record is inherent in CBA and how much is due to other factors. The literature strongly supports the conclusion that $\mathrm{OMB}$, in Republican and Democratic administrations alike, has consistently favored weakening environmental regulations. ${ }^{22}$

Adler's and Posner's (2006) response is that the consensus does not foreclose the possibility that EPA is consistently overzealous, at least when OMB intervenes, and that OMB's consistent direction simply counteracts this bias (p. 121). ${ }^{23}$ If Adler and Posner are right that $\mathrm{CBA}$ makes regulation transparent, one would expect them to come up with strong affirmative evidence, in the form of some regulation revealed by CBA to be clearly overzealous. After all, CBA has been part of government for a long time now.

The available evidence shows that OMB's pattern stems from something other than OMB using accurate CBA to correct a clearly overzealous EPA. First, OMB favors weaker regulation in most cases with no basis on CBA at all (Driesen 2006). ${ }^{24}$ This suggests that part of CBA's role is to justify institutions that are dedicated to weakening regulation regardless of the outcome of analysis. Second, OMB opposed regulation when CBA showed that the regulation would generate monetized benefits exceeding costs. ${ }^{25}$ Third, there is only one recorded case of $\mathrm{OMB}$ pushing for stronger regulation in its history, even though a lot of CBA shows benefits in excess of costs, a sign that a stricter regulation would be optimal in economic terms. ${ }^{26}$ Fourth, where OMB opposed regulation on the basis of a claim that costs really did exceed benefits, a surprisingly infrequent occurrence, $\mathrm{OMB}$ consistently reached this conclusion by rejecting agency valuations and fighting for very low valuations. ${ }^{27}$

\section{Conclusion}

The CBA debate is far from over. But with New Foundations, Adler and Posner have brought a new depth, honesty, and intellectual precision to the table, and begun to transform what has so often been a shouting match into a respectful, if still heated, conversation. Out of this conversation, we can begin to see emerging new questions that have often been ignored in the heat of the fray, but which may offer new paths forward. If welfarism should share the public policy stage with other values, what are those values and how can we incorporate them into decision-making? If CBA is not a moral criterion, but simply an imperfect proxy - a practical tool - then how can we best evaluate how well that tool is working in the real world? Does it tend to counteract existing weaknesses in our political institutions or exacerbate them? And how does it measure up to alternatives? Is it more or less perfect than other decision procedures at approximating what we really care about? Although Adler and Posner have not definitively answered these questions, they have done the scholarly community a great service in New Foundations by raising promising avenues for further theoretical and empirical inquiry.

\section{Notes}

1 Although the three subsequent parts of this review essay are presented in co-authored form, Doug Kysar authored Part I, Amy Sinden authored Part II, and David Driesen authored Part III.

2 To their credit, Adler and Posner (2006) recognize that much theoretical work remains to be done regarding their restricted preferentialist account, referring to the exclusion of otherregarding preferences as "something of a promissory note, since no one has yet fully explained what the difference is between 'self-interested' and 'disinterested' preferences” (p. 49). 
3 This separationist approach is evident in their suggestion that CBA should not include so-called "existence values," typically derived through contingent valuation studies, since respondents to such studies are often expressing their views "as a valuation of the violation of a moral commitment, not as a valuation of an environmental amenity" (Adler \& Posner 2006, pp. 134-135). In other words, unless an environmental benefit would actually impact an individual's welfare, as opposed to comport with their moral or political values, the benefit should not be counted. Again, the problem with this approach lies in the assumption that an unproblematic definition and basis for measurement of "welfare" can be identified.

4 An anonymous reviewer wrote in reference to this passage, "If preferences are no longer treated as exogenous, then I think it makes the problem intractable." Without denying the significance of this concern to the academic project of welfare economics, it bears noting that law's task is often precisely to mediate the gap between theoretical tractability and lived experience.

5 See National Pollutant Discharge Elimination System - Final Regulations to Establish Requirements for Cooling Water Intake Structures at Phase II Existing Facilities, 69 Fed. Reg. 41,576, 41, 660-61 (July 9, 2004).

6 Control of Hazardous Air Pollutants From Mobile Sources, 71 Fed. Reg. 15804, 15907-10 (Mar. 29, 2006).

7 US EPA Office of Air Quality Planning and Standards, Regulatory Impact Analysis of the Final Clean Air Mercury Rule, EPA-452/R-05-003, 3-10 to 3-14 (March 2005). Available from URL: http://www.epa.gov/ttn/ecas/regdata/RIAs/mercury_ria_final.pdf.

8 "The feasibility of distributive weighting has been much debated, without a clear resolution, by welfare economists."

9 See, e.g. Office of Management and Budget, Office of Information and Regulatory Affairs, Progress in Regulatory Reform: 2004 Report to Congress on the Costs and Benefits of Federal Regulations and Unfunded Mandates on State, Local, and Tribal Entities 18 (2004), which discusses major benefits not quantified in the CBA of a rule reducing water pollution from animal feed operations; Parker (2003), which explains the difficulties with non-cancer health effects and ecological effects, and gives numerous examples of failure to count nonquantifiable benefits.

10 See, e.g. Massachusetts v. EPA, 127 S. Ct. 1438, 1462-63 (2007), which holds that the EPA should have made a finding on whether greenhouse gases endanger public health or welfare under the Clean Air Act; Indus. Union Dep't v. Am. Petroleum Inst., 448 U.S. 607, 653 (1980) (plurality opinion), in which the US Supreme Court required the agency to make a finding of significant risk of material health impairment prior to regulation under the Occupational Safety and Health Act.

11 See, e.g. Ethyl Corp. v. EPA, 541 F.2d 1, 10 (D.C. Cir. 1976), which discusses the agency's examination of lead's health effects as part of a finding of endangerment in spite of significant uncertainties and the inability to quantify the effects of lead in gasoline; Ackerman et al. (2005, pp. 160-172), which explains that regulation enacted under an endangerment trigger when benefits could not be quantified generated the data that made CBA possible in later phases of the lead phase-down.

12 Driesen $(2005$, p. 3$)$ characterizes the feasibility principle as embodying a preference for avoiding widespread plant shutdowns.

13 Driesen $(2005$, p. 2) points out that the feasibility principle considers cost in order to identify the maximum feasible level of emission reductions.

14 McGarity (1983) states that costs are "invariably" considered in setting technology-based standards. See, e.g. Kennecott Copper v. EPA, 780 F.2d 445, 456 (4 $4^{\text {th }}$ Cir. 1985), which finds that Congress required consideration of cost in setting technology-based effluent reduction standards under the Federal Water Pollution Control Act.

15 Driesen (2005) justifies this interpretation of the feasibility principle. 
16 Adler and Posner list affiliation as an objective good.

17 Driesen (2005) explains that comparison of costs with firms' economic capabilities, not with benefits, helps predict plant shutdowns.

18 Adler and Posner include emotions on a list of objective goods.

19 Adler and Posner list "control over the environment" as an objective good.

20 See Goodstein (1999) who explains that pollution control requirements often create bluecollar jobs.

21 Bagley \& Revesz (2006, pp. 1268-1269) describe CBA as a "one-way ratchet" that weakens regulation, rather than maximizing net benefits; Driesen (2006, p. 384) concludes after a review of the relevant literature and a fresh assessment of recent experience that CBA proponents within the government "almost invariably use it to weaken regulation" and that cost-benefit criteria in statutes, where they exist, have stymied it altogether; McGarity (2002, p. 2342) states that the process of CBA has "thoroughly stymied government action under" TSCA and FIFRA; Johnston (2002, p. 1392) states that the EPA had only re-registered two of 19,000 older pesticides by 1992 under FIFRA; Hornstein (1993, pp. 436-437 \& n.395). For a discussion of the recent contrary sounding claims, see Driesen (2006, pp. 354-364, 380-384); Bagley and Revesz (2006, pp. 1277-1280), which discuss the prompt letters that CBA advocates sometimes cite as evidence of CBA increasing the stringency of regulation.

22 See Gen. Accounting Office, Regulatory Reform: Implementation of the Regulatory Review Executive Order 13 (1996), which provides three examples of pro-industry regulatory changes suggested by OMB under Clinton, but not pro-environmental changes.

23 Adler and Posner actually state that if EPA tends to overregulate then "it is proper for OMB to push for greater stringency" (p. 121, emphasis added). I am assuming that this is a typo, and that Adler and Posner meant that overregulation properly triggers a push for lesser, not greater, stringency.

24 Driesen (2006, pp. 376-378) explains that OMB consistently opposed rules when data gaps prevented the completion of $\mathrm{CBA}$ and even when a rule mandating a transfer fee generated no societal costs.

2569 Fed. Reg. 41, 576, 41, 660-61 (July 9, 2004) at 369-70.

2669 Fed. Reg. 41, 576, 41, 660-61 (July 9, 2004) at 384 concludes that with the single exception of the regulation of lead in gasoline, CBA acted as a one-way ratchet, sometimes weakening but never strengthening regulation.

27 69 Fed. Reg. 41, 576, 41, 660-61 (July 9, 2004) at 369-372 finds that the EPA found benefits exceeding costs in all six cases where it conducted a CBA, but that OMB resisted that conclusion in three cases, and discusses specific cases.

\section{References}

Ackerman F, Heinzerling L, Massey R (2005) Applying Cost-benefit Analysis to Past Decisions: Was Environmental Protection Ever a Good Idea? Administrative Law Review 57, 155-192.

Adler MD (1998) Incommensurability and Cost-benefit Analysis. University of Pennsylvania Law Review 146, 1371-1418.

Adler MD (2000) Beyond Efficiency and Procedure: A Welfarist Theory of Regulation. Florida State University Law Review 28, 241-338.

Adler MD (2003) Risk, Death and Harm: The Normative Foundations of Risk Regulation. Minnesota Law Review 87, 1293-1445.

Adler MD (2004) Cost-benefit Analysis, Static Efficiency, and the Goals of Environmental Law. Boston College Environmental Affairs Law Review 31, 591-604.

Adler MD, Posner EA (1999) Rethinking Cost-benefit Analysis. Yale Law Journal 109, 165-247.

Adler MD, Posner EA (2000) Implementing Cost-benefit Analysis When Preferences are Distorted. Journal of Legal Studies 29, 1105-1145. 
Adler MD, Posner EA (2006) New Foundations of Cost-benefit Analysis. Harvard University Press, Cambridge, MA.

Arrow KJ et al. (1996) Is There a Role for Benefit-cost Analysis in Environmental, Health, and Safety Regulation? Science 272, 221-222.

Bagley N, Revesz R (2006) Centralized Oversight of the Regulatory State. Columbia Law Review 106, 1260-1329.

Baker CE (1975) The Ideology of the Economic Analysis of Law. Philosophy $\prec$ Public Affairs 5, 3-48.

Bishop RC (1978) Endangered Species and Uncertainty: The Economics of a Safe Minimum Standard. American Journal of Agricultural Economics 60, 10-18.

Bressman LS, Vandenbergh MP (2006) Inside the Administrative State: A Critical Look at the Practice of Presidential Control. Michigan Law Review 105, 47-99.

Breyer S (1993) Breaking The Vicious Circle: Toward Effective Risk Regulation. Harvard University Press, Cambridge, MA.

Calabresi SG, Rhodes KH (1992) The Structural Constitution: Unitary Executive, Plural Judiciary. Harvard Law Review 105, 1153-1216.

Coleman JL (2003) Book Review, The Grounds of Welfare. Yale Law Journal 112, 1511-1543.

Cowen T, Parfit D (1992) Against the Social Discount Rate. In: Laslett P, Fishkin JS (eds) Justice Between Age Groups and Generations, pp. 144-161. Yale University Press, New Haven.

Doremus H (2005) Science Plays Defense: Natural Resource Management in the Bush Administration. Ecology Law Quarterly 32, 249-305.

Doremus H (2008) Scientific and Political Integrity in Environmental Policy. Texas Law Review 86, $1601-1653$.

Driesen DM (2005) Distributing the Costs of Environmental, Health, and Safety Protection: The Feasibility Principle, Cost-benefit Analysis, and Regulatory Reform. Boston College Environmental Affairs Law Review 32, 1-94.

Driesen DM (2006) Is Cost-benefit Analysis Neutral? University of Colorado Law Review 77, 335-403.

Freeman AM III (1993) The Measurement of Environmental and Resource Values. Resources for the Future, Washington, DC.

Froomkin M (1994) The Imperial President's New Vestments. Northwestern University Law Review $88,1346-1376$.

Gen. Accounting Office, Regulatory Reform: Implementation of the Regulatory Review Executive Order 13 (1996).

Goodstein E (1999) The Trade-off Myth: Fact and Fiction About Jobs and the Environment. Island Press, Washington, DC.

Hahn RW, Dudley PM (2007) How Well Does the U.S. Government Do Cost-benefit Analysis? Environmental Law \& Policy Review 1, 192-211.

Heinzerling L (1999) Discounting Our Future. Land and Water Law Review 34, 39-74.

Heinzerling L (2000) The Rights of Statistical People. Harvard Environmental Law Review 24, 189-207.

Heinzerling L (2006) Knowing Killing and Environmental Law. New York University Environmental Law Journal 14, 521-534.

Heinzerling L, Steinzor R (2004) A Perfect Storm: Mercury and the Bush Administration, Part II. Environmental Law Reporter 34, 10,485-10,497.

Hornstein DT (1993) Lessons from Federal Pesticide Regulation on the Paradigms and Politics of Environmental Law Reform. Yale Journal on Regulation 10, 369-446.

Horowitz JK, McConnell KE (2002) A Review of WTA/WTP Studies. Journal of Environmental Economics and Management 44, 426-447.

Howarth RB (1995) Sustainability Under Uncertainty: A Deontological Approach. Land Economics $71,417$. 
Johnston JS (2002) A Game Theoretic Analysis of Alternative Institutions for Regulatory Costbenefit Analysis. University of Pennsylvania Law Review 150, 1343-1411.

Kaplow L, Shavell S (2002) Fairness versus Welfare. Harvard University Press, Cambridge, MA.

Kelman MG (2005) Hedonic Psychology and the Ambiguities of Welfare. Philosophy \& Public Affairs 33, 391-412.

Kennedy D (1981) Cost-benefit Analysis of Entitlement Problems: A Critique. Stanford Law Review $33,387-445$.

Knetsch JL (1990) Environmental Policy Implications of Disparities between Willingness to Pay and Compensation Demanded Measures of Values. Journal of Environmental Economics and Management 18, 227-237.

Kysar DA (2007) Discounting ... On Stilts. University of Chicago Law Review 74, 119-138.

Kysar DA (2009a) Regulating from Nowhere: Environmental Law and the Search for Objectivity. Yale University Press, New Haven, CT (in press).

Kysar DA (2009b) Fish Tales, In: Alternative Approaches to Regulatory Impact Analysis: A Dialogue Between Advocates and Skeptics of Cost-Benefit Analysis, Resources for the Future (in press).

Leff A (1974) Economic Analysis of Law: Some Realism About Nominalism. Virginia Law Review $60,451-482$.

Lessig L, Sunstein CR (1994) The President and His Administration. Columbia Law Review 94, 1-119. Loasby BJ (1999) Knowledge, Institutions and Evolution in Economics. Routledge, New York, NY.

McGarity TO (1983) Media-quality, Technology, and Cost-benefit Balancing Strategies for Health and Environmental Regulation. Law \& Contemporary Problems 46, 159-233.

McGarity TO (2002) Professor Sunstein’s Fuzzy Math. Georgetown Law Journal 90, 2341-2377.

Mishan EJ (1976) Cost Benefit Analysis. Praeger, New York.

Norgaard RB, Howarth RB (1991) Sustainability and Discounting the Future. In: Costanza R (ed) Ecological Economics: The Science and Management of Sustainability, pp. 88-101. Columbia University Press, New York.

Norton B, Costanza R, Bishop RC (1998) The Evolution of Preferences: Why “Sovereign" Preferences May Not Lead to Sustainable Policies and What to Do About It. Ecological Economics 24, 193-211.

Office of Management and Budget (2003) Circular A-4 (Sept. 17, 2003).

Office of Management and Budget, Office of Information and Regulatory Affairs, Progress in Regulatory Reform (2004) 2004 Report to Congress on the Costs and Benefits of Federal Regulations and Unfunded Mandates on State, Local, and Tribal Entities 18 (2004).

Page T (1997) On the Problem of Achieving Efficiency and Equity, Intergenerationally. Land Economics 73, 580-596.

Parker RW (2003) Grading Government. University of Chicago Law Review 70, 1345-1485.

Percival RV (2001) Presidential Management of the Administrative State: The Not-so-unitary Executive. Duke Law Journal 51, 963-1013.

Posner EA (2001) Controlling Agencies with Cost-Benefit Analysis: A Positive Political Theory Perspective. University of Chicago Law Review 68, 1137-1199.

Randall A, Farmer MC (1995) Benefits, Costs and the Safe Minimum Standard of Conservation. In: Bromley D (ed) The Handbook of Environmental Economics, pp. 26-44. Blackwell, Cambridge, MA.

Revesz R (1999) Environmental Regulation, Cost-benefit Analysis, and the Discounting of Human Lives. Columbia Law Review 99, 941-1017.

Revesz R, Livermore M (2008) Retaking Rationality: How Cost-benefit Analysis can Better Protect the Environment and Our Health. Oxford University Press, New York.

Sagoff M (2004) Price, Principle, and the Environment. Cambridge University Press, Cambridge, UK.

Sen A (1970a) Collective Choice and Social Welfare. Holden-Day, San Francisco.

Sen A (1970b) The Impossibility of a Paretian Liberal. Journal of Political Economy 78, 152. 
Sinden A (2004) Cass Sunstein's Cost-benefit Lite: Economics for Liberals. Columbia Journal of Environmental Law 29, 191-241.

Sinden A (2005) In Defense of Absolutes: Combating the Politics of Power in Environmental Law. Iowa Law Review 90, 1401-1511.

Sunstein CR (2002a) The Arithmetic of Arsenic. Georgetown Law Journal 90, 2255-2303.

Sunstein CR (2002b) The Cost-benefit State: The Future of Regulatory Protection. American Bar Association, Chicago, IL.

Symposium (2008) The Role of the President in the Twenty-first Century. Boston University Law Review 88, 321-326.

Tribe LH (1972) Policy Science: Analysis or Ideology? Philosophy \& Public Affairs 2, 66-110.

Tribe LH (1974) Ways Not to Think About Plastic Trees: New Foundations for Environmental Law. Yale Law Journal 83, 1315-1348.

Trumbull WN (1990) Who Has Standing in Cost-benefit Analysis? Journal of Policy Analysis and Management 9, 201-218.

US Department of Transportation (2006) National Highway Traffic Safety Administration, Final Regulatory Impact Analysis, Corporate Average Fuel Economy and CAFÉ Reform for MY 2008-2011 Light Trucks VIII-64 to VIII-65 (March 2006). [Last accessed 17 Mar 2009.] Available from URL: http://www.nhtsa.dot.gov/staticfiles/DOT/NHTSA/Rulemaking/Rules/Associated\%20Files/ 2006_FRIAPublic.pdf.

Weitzman M (2007) The Stern Review of the Economics of Climate Change. Journal of Economic Literature 45, 703-724.

\section{Cases cited}

Ethyl Corp. v. EPA, 541 F.2d 1, 10 (D.C. Cir. 1976).

Indus. Union Dep't v. Am. Petroleum Inst., 448 U.S. 607, 653 (1980).

Kennecott Copper v. EPA, 780 F.2d 445, 456 (4th Cir. 1985).

Massachusetts v. EPA, 127 S. Ct. 1438, 1462-63 (2007).

Tennessee Valley Authority v. Hill, 437 U.S. 153 (1978).

Whitman v. American Trucking Associations, 531 U.S. 457 (2001).

\section{Laws cited}

Control of Hazardous Air Pollutants From Mobile Sources, 71 Fed. Reg. 15804, 15907-10 (Mar. 29, 2006).

National Pollutant Discharge Elimination System - Final Regulations to Establish Requirements for Cooling Water Intake Structures at Phase II Existing Facilities, 69 Fed. Reg. 41,576, 41, 660-61 (9 July 2004). 
Copyright of Regulation \& Governance is the property of Blackwell Publishing Limited and its content may not be copied or emailed to multiple sites or posted to a listserv without the copyright holder's express written permission. However, users may print, download, or email articles for individual use. 